\title{
Redakční rada děkuje všem uvedeným recenzentům, kteři se v roce 2005 podíleli na posuzování rukopisů poslaných do Cor et Vasa
}

\section{SEZNAM RECENZENTŮ}

prof. MUDr. Michael Aschermann, DrSc. MUDr. Jan Bělohlávek, CSc. MUDr. Jan Bytešník, CSc. doc. MUDr. Miroslav Bulvas, CSc. doc. MUDr. Renata Cífková, CSc. prof. MUDr. Roman Čerbák, CSc. prof. MUDr. Jan Černý, CSc. doc. MUDr. Richard Češka, CSc. MUDr. Robert Čihák, CSc. prof. MUDr. Jan Dominik, CSc. MUDr. Petr Frídl, CSc. prof. MUDr. Pavel Gregor, DrSc. MUDr. Tomáš Hájek prof. MUDr. Jaroslav Hejnal, DrSc. MUDr. Miroslav Chochola, CSc. MUDr. František Jurán̆ prof. MUDr. Josef Kautzner, CSc. MUDr. Jiří Kettner, CSc. doc. MUDr. Ivan Málek, CSc. MUDr. Eva Mandysová, CSc. MUDr. Tomáš Marek, CSc. prof. MUDr. Jaroslav Meluzín, CSc. MUDr. Petr Neužil, CSc. prof. MUDr. Petr Niederle, DrSc. prof. MUDr. Bohuslav Oštádal, DrSc. MUDr. Jan Pitha, CSc. prof. MUDr. Hana Rosolová, CSc. doc. MUDr. Vladimír Soška, CSc. MUDr. Jiří Spáčil, CSc.

prof. MUDr. Zbyněk Straka, CSc. MUDr. Stanislav Šimek, CSc. MUDr. Zdenka Škodová, CSc. prof. MUDr. Jaroslav Šimon, DrSc. MUDr. Jan Šochman, CSc. doc. MUDr. Rudolf Špaček, CSc. MUDr. Jaroslav Špatenka, CSc. MUDr. Vlastimil Vančura prof. MUDr. Ivan Vaněk, CSc. doc. MUDr. Josef Veselka, CSc. prof. MUDr. Jiří Vitovec, CSc. prof. MUDr. Jan Vojáček, DrSc. prof. MUDr. Jiří Widimský, DrSc., sen. prof. MUDr. Jiří Widimský, CSc., jun. prof. MUDr. Petr. Widimský, DrSc. MUDr. Michael Želízko, CSc.

prof. MUDr. Vladimír Staněk, CSc., za redakční radu 